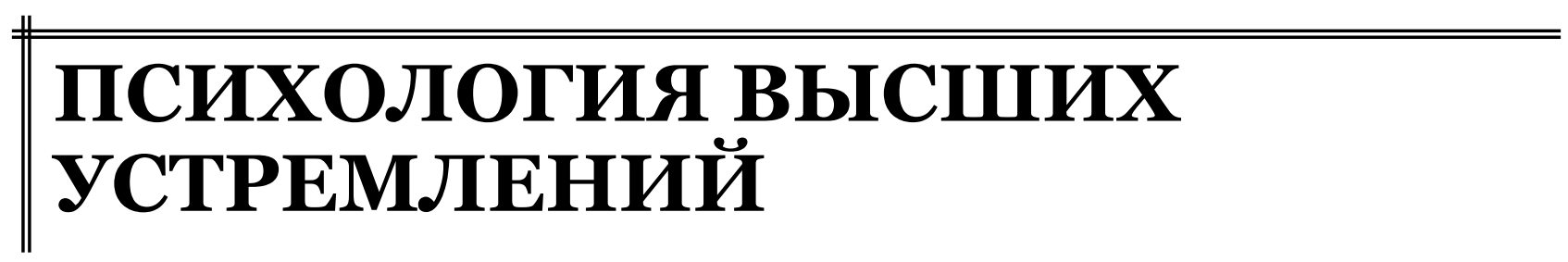

A.С. Энфи (A.S. Enfi)

\title{
SUBLIMATION PSYCHOLOGY: ESSENCE CODING THEORY AND SYMPHO-ELECTRONIC MUSIC AS TOOLS FOR DEEP PSYCHOTHERAPY IN ART-HUMANITARIAN PRACTICE
}

Review. The article addresses the need for a new direction of psychology known as "sublimation psychology", prerequisites for the creation of which have emerged in the scientific discoveries of the last decades in the fields of psychoneuroendocrinology, psychoneurology and psychogenetics. In the context of developing sublimation psychology, we have investigated the various properties and characteristics of "Sympho-Electronic Music" (SEM) - a new musical genre, which has a strong essence impact potential. We analyze the advantages of using SEM in the deep-essence psychotherapy of art-humanitarian practice (AHP), based on the implementation of the major principles and fundamental medical and psychological aspects of Essence Coding Theory (ECT). Primarily, the article uses a complex methodological concept, in which the basal toolkit of holistic meta-heuristic ECT doctrine takes a central, key position. We show a fundamental difference of sublimation psychology from all other areas of psychology, expressed by its explicit focus on the scope of various ethical attributions and aesthetic competencies implemented in AHP. In the context of developing various aspects of AHP, we introduce new concepts, such as "essence code", "essence psycho-neuroendocrine status", "essence R-E neuroprocessing", "essence genome-hormonal reception", "essence transmutation", "vital information system", "ethical levels", "passionary-evolutionary ethics", "sublimation aesthetics", "exo-psychological control", "dormant genomic programs", "matrix of essence standards", "detector of essence errors", "code of spiritual rank", "aesthetic-sublimation insight", "immortalization index", "noematic theurgy" and others. We have identified reasons for which the psychotechnics of art-humanitarian practice should use music created with digital technology, and especially the music of the pioneering genre SEM, closely associated with such new musicological concepts as "timbrekeeping", "emotive typology of timbre", "class of organs","sympho-electronic organ", "sonoristic analysis", "sonoristic matrix", "sonoristic bench mark", "sacral acoustics", "coding-numeric score", "coding-numeric aesthetics", etc.

Keywords: passionary-evolutionary ethics, noematic theurgy, aesthetic-sublimation insight, sympho-electronic music, essence coding theory, art-humanitarian practice, sublimation psychology, spiritual rank code, immortalization index, coding-numeric score.

cientific discoveries in recent decades in the fields of psychoneuroendocrinology and psychogenetics evidence informational functions of neuropeptide hormones that act as a material substrate capable of forming and carrying certain psycho-codes ${ }^{1}$. The comprehensive development of a hypothesis about the essential nature of

Belkin A. Hormones and the unconscious // Psikhoanaliticheskiy vestnik. 2001. № 9. P. 70-90; Article with comments by A.Enfi // Online version available at: http://aramenfi.narod.ru/ articls.belkin1.html. these codes, which, when translated into the genomic structure of a person serve as an assessment marker of its ethically important behavioral patterns, led to the creation of Essence Coding Theory (ECT) ${ }^{2}$. ECT is an integrated metascientific and heuristic doctrine, according to which the essential parameters of each person during his/her life in the physical plane are subjected to the process of specific bio-informatic encoding, resulting, inter alia, in the formation of a

Enfi A. Essence Coding Theory (a monograph). Art-Humanitarian Centre. M., 1991. 
code matrix of a potentially eternal information substance, which, in the terminology of the ancient and emerging anthropological and cosmological teachings, is recognized under the name "the immortal soul of a man". In the context of ECT, the concept of "essential parameters" is defined as a set of the most important qualities of ethical and creative-cognitive attribution relevant to the progress of mankind, and therefore being "under the jurisdiction" of the objective informational Conscience Act, which include: dignity, integrity, justice, identity, the ability to love and be compassionate, empathy, generosity, will, creativity, passionarity, perfectionism, etc. ${ }^{3}$.

In connection with all of the above, the need for a new direction of psychology, which differs from all the previously known directions by its pronounced orientation towards the sphere of different ethical attributions and competences, seems quite natural.

Inheriting the soteriological ideal of Grace-Transfiguration-Redemption and appealing to Thanatos's entelechy of essential immortality, the negentropic concept of such psychology is called to approve the passionary-evolutionary ethics of the Spiritual Ascension (sublimation) to the image and likeness of God at the new epistemological level ${ }^{4}$. And since the unique "transcoder" capable of identifying and implementing this Image with the highest adequacy is the transcendental apperception only intent to the imagination and imagination of the artist, the part of the transformational tool of aesthetic and sublimation insight in the concept of the psychology area being developed must be fulfilled by Art, and first of all by Music, which is the most universal metalanguage of intuitive and visionary cognition of Existence and mystical comprehension of Being.

Indeed, the neurophysiological studies show that music, acting as a matrixed hyper-program, can rebuild relations between the hemispheres of the brain, control the state of its limbic system and the default network of neurons ${ }^{5}$, as well as the synthesis of a number of neurotransmitters and neurohormones (hypophyseal, epiphyseal, hypothalamic and cortex), which, being

\footnotetext{
3 Enfi A. Essence Coding Theory as an ethical basis for the ideological paradigm of the 3rd Millennium // Proceedings: Proceedings of the International Conference "Valeology and Eniology of the 3rd Millennium”, Yalta / Simferopol, 2007.

4 Vysheslavtsev B. Ethics of transfigured Eros. Problems of Law and Grace // M.: Respublika, 1994.

5 Bondaremko V., Yevin I. Attractor network model of music tonality and controlling chaos in the brain, N.Y., 2006.
}

the vectors of essential situational codes, determine the ethical behavior of people and take part in shaping their essential-informational matrix. It goes without saying that in this aspect, the value of music can be polar, and its only objective criterion is the scientifically verifiable "immortalization index", expressed by the ability to help people realize their potential of essential immortality, or vice versa - to annihilate it.

All this allows us to introduce the concept of "sublimation psychology" as a designation of a new, ethically and aesthetically oriented (ethically and aesthetically centered) area of psychology ${ }^{6}$ to the scientific discourse.

Such a new musicology concept as "SymphoElectronic Music", abbreviated as "SEM", which actively gains a foothold in discursive spaces of domestic art, takes on special significance in the context of sublimation psychology?

SEM is a type of serious intellectual music of a sufficiently large conceptual form, electronic in its stylistic, instrumental and structural specificity, and symphonic in its compositional attribution and internal content, deepest in terms of philosophy and most significant in terms of worldview, so that it:

- fully meets the criteria of the "symphonism" concept, as defined by this fundamental musicological term by its author, the Academician B.V. Asaf'ev ${ }^{8}$; - refers to the specific electronic and musical computer technologies as its own key means of implementing all the necessary (ideological, psychological, aesthetic, textural, etc.) attributes of symphonism.

To us, SEM is of particular interest due to the fact that today this music is used as a basic transformational tool of art-humanitarian techniques and practices applicable in the field of deep-essential psychotherapy, the object of which is primarily a variety of serious diseases that have a pronounced ethical and spiritual conditioning.

"Art-humanitarian" is a humanistically oriented inter-disciplinary creative activity, which takes place "at the crossroads" of different art forms, natural science, medicine, philosophy, psychology, sociology and theology, and uses high technology. The result of this

\footnotetext{
6 Enfi A. Sublimation psychology (a monograph). Published by the Art-Humanitarian Centre. M., 2013.

Enfi A. What is "sympho-electronic music"? // Music and time. 2011. № 4. P. 67-71.

8 Asaf'ev B. Symphonism as a problem of modern musicology, L., 1926.
} 


\section{Психология высших устремлений}

activity has beneficial effects on the spiritual development of an individual ${ }^{9}$.

Based on the implementation of the major principles and fundamental medical and psychological aspects of ECT, it is said that art-humanitarian techniques and practices are so named precisely because (by definition) they are most directly related to art as a form of intuitive and visionary cognition of Being and mystical comprehension of Entity, and first of all to music - as a universal transformational tool capable of effectively influencing the formation of the spiritual body in the most direct, immediate and subtle way. These practices are designed primarily to help people recognize their Higher Self dwelling in the bosom of the Divine Presence. It is only on condition that the Higher Self of a person (the Creator's Aspect) realizes itself involved in the Essence of the Supreme Reality - i.e. transcendental, indestructible and immortally Absolute - that human consciousness can expand and grow strong so that the force of its impact will be able to deprive almost any disease of mental ground by inducing and catalyzing the healing processes in the body, i.e. for it to gain integrity.

It should be clearly understood that by implementing the psychotherapeutic potential of art-humanitarian techniques we are not dealing with just one type of aesthetics therapy; it is not the usual "relaxation" or "meditative" (in the common interpretation of the term) treatments and practices, but a much more serious, complex and deep use (including in the most severe clinical situations) of the most sacral properties of music and other art forms. After all, by subjecting the patient's consciousness to the most diverse exposure levels (pre-anesthetic, cathartic, transpersonal, integration, etc.), art-humanitarian techniques are designed to provide a comprehensive solution to all the challenges that would have to be addressed by Gestalt therapy, imago therapy, cognitive and rational therapy (with a certain verbal support), indirect suggestion and psychosynthesis.

It is clear that for such a large-scale implementation of psychotherapeutic objectives and goals, it would be an absolute profanation to use, for example, some light or popular, even highly artistic music, obsessed with its "aesthetics", for listeners to passively enjoy its emotive flow, offering a carefree and enjoyable "consumption".

On the contrary, art-humanitarian creativity should encourage patients to make significant resolute efforts to achieve synergy (co-working), without which the achievement of the necessary spiritual break-

9 Enfi A. Art-humanitarian practice (a monograph). Published by the Art-Humanitarian Centre. M., 1999. through capable of withdrawing a seriously ill man from a terrible existential crisis and deadlock would be simply impossible; it also aims at opening the door to bright spiritual worlds by making its listeners face the frighteningly bleak phenomena of existence. Thus, with the help of art-humanitarian techniques, a person turns into his/her own powerful spiritual healer!

Art-humanitarian creativity is associated with the term "Theurgic Art" and focuses on the practical implementation of the highly transformational idea about the "awakening of a spiritually dormant man" put forward by the founder of the "School of the Fourth Way" ("Way of Conscience"), G.I. Gurdjieff. At the same time, Gurdjieff recognized only "objective" art as a tool for spiritual transmutation; i.e. something which properly embeds all the sacred connections and essential meanings.

And since we have not yet touched the issue of "coding formats" in art-humanitarian techniques, it would seem that all of their considered qualities can be provided by "Asaf'ev symphonism" SEM alone; therefore they don't have any direct and immediate relationship with the specifics of this purely electronic music. The most important properties and qualities of arthumanitarian concepts that make them particularly valuable for use in the area of deep-essential psychotherapy are also defined by the principal factor, that during the creation of art-humanitarian products, their author, being a sensitive conductor of spiritual energy (which, along with individual mystical experience, is the only thing that gives him the right to engage in spiritual healing), had to overcome this "simulated" fragmentation of his own consciousness and draw himself out of a psychosomatic disease.

It is when the unique properties, features and advantages of SEM step to the forefront that certain advantages over all other types of music in the context considered by us are provided ${ }^{10}$.

The fact of the matter is that the holistic and studio nature of creating SEM works makes it possible for their author to act simultaneously as a composer, multiartist, conductor and engineer of his music without any intermediaries or interpreters, which gives him complete freedom of intuitive creativity and contributes to the level of ideological sincerity, spiritual intimacy and psychological depth unprecedented in musical culture hitherto... ${ }^{11}$.

10 Enfi A. Sympho-electronic music: Psychological aspects // Psikhologicheskaya gazeta. 20.05.2011.

11 Enfi A. Sympho-electronic music: Social aspects // Sotsiosfera. 2011. № 2. P. 18-24. 


\section{Психология и психотехника 2(65) • 2014}

Thus, with a spiritual charge of spontaneous intuitive creativity aimed at self-healing and spiritual liberation, art-humanitarian concepts acquire the status of effective "Evolutionary Prayer", designed to assist humanity in its need of spiritual healing; the fact that these techniques are aimed at the induction of cathartic and penitential states of consciousness in patients who are able to adequately perceive their "energy aesthetics", makes art-humanitarian techniques effective in relation to many clinical situations, because almost every one of them is largely determined by ethical and spiritual etiology factors.

On a purely physiological level, the effect of arthumanitarian techniques is primarily expressed by mobilization of the immune system, which thereby gains strength so that it is already beginning to independently suppress and eliminate the primary cause of disease - a result which, in terms of ECT, is caused by a very intensive influence of abundantly structured "good" essential codes on the genetic apparatus of patients' cells, humorally transmitted to these cells by the corresponding hormones.

The possibility of such a mobilization of the immune system is due to the evolutionary ethical terms and aspects of ECT, methodologically close and in tune with the concept of "search activity", put forward by V.S. Rotenberg, working in the field of psychophysiology and psychoneuroimmunology ${ }^{12}$.

It is clear, of course, that many other psychoneuroimmunological factors identified in the long-term clinical observations and biochemical studies play a very important part in this mobilization process, such as:

- the effect of various psycho-emotional states on the operation of the entire immune system and its central organs - i.e. the thymus and the bone marrow;

- the involvement of neurotransmitter systems and their main agents, such as serotonin, dopamine, GABA, etc. in the process of psycho-immunological modulation;

- the secretion of different polypeptide hormones, including oxytocin and vasopressin, by activated T-lymphocytes and other immune cells;

- the participation of various neuropeptide hormones in the process of the bidirectional interaction of the neuroendocrine and immune systems, which results in pronounced dynamics of the immune response when the body's hormonal status changes.

12 Rotenberg V. Psycho-neuroimmunology: A new dimension to an old problem // Priroda. 1991. № 2. P. 29-34.
Another extremely important feature of art-humanitarian techniques that turns them into a unique tool of psychotherapeutic influence (including in severe clinical cases) is a strategic factor for their existential relevancy: organically originating in the semantic extreme of a particular socio-cultural environment, with all its pressing problems, these techniques are "sharpened" under the direct authorization of the spiritual and psychological conflicts that are generated by social and cultural realities, similar in their problems to those of their "parent" environment.

It is clear that the primary (essential) reasons for these conflicts caused by the "evolutionary-ethical failure" of patients can be eliminated only in the nerve of mental-semiotic and artistic influence, which is entirely adequate to the ideological imperatives and spiritual challenges of the era, using the most effective "cathartic toolkit", whose part today is claimed by $\mathrm{SEM}^{13}$. It is not surprising that the idea of non-denominational "universal musical religion" brought forward by K. Stockhausen, and the "musical psychofield" by J. Cage, emerged from the ideological grounds which preceded the concept of SEM. Back then, however, during the active creative and philosophical search of Varese, Cage, Stockhausen, Xenakis and other conceptual composers, who became pioneers of electronic music, all those ideas were still quite raw and vague, and in some cases even deliberately simulative; today they have already gained maturity and a clear ideological justification - not only in the humanitarian sphere, but also in natural science ${ }^{14}$.

Thus, nowadays it is SEM that has been granted the status of innovative art, designed to exercise the spiritual dimension of Being with maximum completeness and adequacy, thus serving as the thinnest and most accurate transformational tool of deep psychological impact; the latest lighting and multimedia technologies contribute to the visual concentration and transformation of the sound image.

The priority of using SEM in art-humanitarian psychotechnics, as music composed with the help of digital technology, is explained by the following reasons:

1. The tropic of artificial neurocomputing interfaces operation shows that our brain is the organ of information and analysis that uses the method of mathematical modeling of the Fourier series, and

\footnotetext{
13 Enfi A. Sympho-electronic music is Russia's priority // The pedagogy of art. 2012. № 3 .

14 Enfi A. Sympho-electronic music: Genesis // Problems of musical science. 2013. № 1. P. 36-41.
} 


\section{Психология высших устремлений}

therefore it is digital, rather than analog signal information, that is natural for it: wave pulses arising in the cortex serve as the source for building the cerebral holographic recording, quantized and encoded on a set of interacting neurons ${ }^{15}$. That is, in terms of sound perception, our brain acts as the analogto-digital converter (ADC); therefore, no matter what music we listen to, even if it is initially analog, the brain will convert it to digital; in this form, it will affect the neuroendocrine system, participating in the formation of our essential hormonal codes.

2. Any digitized music is a system of numerical codes, which look like "a coding score". Of course, it is impossible to visually read and "hear" such a score in the same way as we do a musical one, but a professional job related to digital sound in the field of academic electronic music forms an intuitive perception of this very significant phenomenon, which could be metaphorically described as an "aesthetic sense of numbers".

3. Apart from the purely technical advantages, serious electronic music has many artistic advantages: tonal, textural, intonational, dynamic, expressive, shading etc., which, of course, provide the possibility of obtaining very delicate and precise parameters of digital encoding; in turn, it is directly reflected in the richness and quality of digital music coding scores, and hence in its value and effectiveness in terms of the essential impact.
4. Composition in the field of digital music suggests negentropic work on "sonoristic cultivation" in the form of intelligent design, organizing and structuring various sound elements used primarily for the creation of artistic timbres, maximally purified from musically harmful "information noise".

5. The adequacy of expressive means of conceptual electronic music in progressive scientific and technological reality adds an additional divination potential of Cosmic Ascension to the Sublimating Image it creates. Of course, the main thing here is the "rank" of a composer who, according to the ECT, correlates it with his spiritual rank, provided the composers are congenial in writing traditional and electronic music; the essential impact of the latter is higher.

As an example of typical SEM works that have been successfully used in spiritual, developing and psychotherapeutic practice for many years, we can specify the sympho-electronic poem "Gurdjieff", created by the author of this article and his conceptual work of the large form "Spirit Lap-I". The rich history of using this music in psychotherapeutic practice shows that when it is listened to properly, the motivation of patients to overcome many psychological problems significantly increases; physiological, primarily immune, resistance of the body in its fight against a broad spectrum of various diseases - up to the most serious forms of cancer pathology - increases substantially as well ${ }^{16}$.

\section{References (transliteration):}

1. Belkin A. Hormones and the unconscious // Psikhoanaliticheskiy vestnik. 2001. № 9. P. 70-90. Article with commentsby A. Enfi // Online version available at: http://aramenfi.narod.ru/articls.belkin1.html.

2. Enfi A. Essence coding theory (a monograph). Art-Humanitarian Centre. M., 1991.

3. Enfi A. Essence coding theory as an ethical basis for ideological paradigm of the 3rd Millennium // Proceedings: Proceedings of the International Conference «Valeology and Eniology of the 3rd Millennium», Yalta / Simferopol, 2007.

4. Vysheslavtsev B. Ethics of transfigured Eros. Problems of the Law and Grace. M.: Respublika, 1994.

5. Bondarenko V., Yevin I. Attractor network model of music tonality and controlling chaos in the brain. N.Y., 2006.

6. Enfi A. Sublimation psychology (a monograph). PublishedbyArt-Humanitarian Centre. M., 2013.

7. Enfi A. What is "sympho-electronic music"? // Music and time. 2011. № 4. P. 67-71.

8. Asaf'evB. Symphonism as a problem of modern musicology. L., 1926.

9. Enfi A. Art-humanitarian practice (amonograph). PublishedbyArt-Humanitarian Centre. M., 1999.

15 Evin I. Music and the brain. Compilation: languages of science - languages of art. M.: RHD, 2004.
16 Garyaev P., Enfi A. Ethics, Spirituality... Oncology, HIV (Reshaping the medical problems in the light of Linguistics, Wave Genetics and Essence Coding Theory) // New Medical Technologies / New Medical Equipment. M.: Medizdat, 2010. № 11. P. 51-72. 
10. Enfi A. Sympho-electronicmusic: psychological aspects // Psikhologicheskaya gazeta. 20.05.2011.

11. Enfi A. Sympho-electronicmusic: social aspects // Sotsiosfera. 2011. № 2. P. 18-24.

12. Rotenberg V. Psychoneuroimmunology: a new dimension to an old problem // Priroda. 1991. № 2. P. 29-34.

13. Enfi A. Sympho-electronicmusicis Russia's priority // Pedagogy of art. 2012. № 3.

14. Enfi A. Sympho-electronicmusic: Genesis // Problems of musical science. 2013. № 1. P. 36-41.

15. Yevin I. Music and the brain. Compilation: Languages of science - languages of art. M.: RHD, 2004.

16. Garyaev P., Enfi A. Ethics, Spirituality... Oncology, HIV (Reshaping the medical problems in the light of Linguistics, Wave Genetics and Essence Coding Theory) // New Medical Technologies / New Medical Equipment. M.: Medizdat, 2010. № 11. P. 51-72.

17. Adorno Th.W. Philosoplue der Neuen Musik. Frankfurt a M., 1958.

18. Arbid, M.A: Brains, machines and mathematics. New York: Mc. Graw-Hill, 1964.

19. Attneave, F.: Application of information theory to psychology. New York: Holt, 1959.

20. Brambring, M.: Technical and practical utilization of electronic mobility aids for the blind. I Handicappinstitutet. (Eds.) June, 1974.

21. Brindley, G.S. \& Ewin, W.C. The sensation produced by electrical stimulation of the visual cortex. In Sterling, T.D., et al. (Eds.) Visual Prosthesis. New York: Academic Press, 1971.

22. Beck, F. and Eccles, J.C. (1992) Quantum aspects of brain activity and the role of consciousness. Proc. Natl. Acad. Sci. USA 89(23):11357-11361.

23. Cohen, J.E.: Information theory and music. Behavioural Science, 1962, 7(12) 137-163.

24. Eccles, J.C. (1992) Evolution of consciousness. Proc. Natl. Acad. Sci. (89)7320-7324.

25. Grof, S., Spiritual Emergency: When Personal Transformation Becomes a Crisis edited by StanislavGrof and Christina Grof (J.P. Tarcher, Los Angeles, CA, 1989, Putnam Publications).

26. Hameroff, S., Penrose R., Orchestrated Objective Reduction of Quantum Coherence in Brain Microtubules: The «Orch OR» Model for Consciousness.// Mathematics and Computer Simulation 40:453-480, 1996.

27. Jacobson, H.: Information and the human ear. Journal of the Acoustical Society of America, 1951, 23, 463-471.

28. Lundin, R.W.: An objective psychology of music. New York: Press, Ronald, 1953.

29. Moles, A., Information theory and aesthetic perception. Chicago: University of Illinois Press, 1966.

30. Pribram, K.H.: (Ed.). Brain and behaviour. Vols. 1, 2 \& 4. Victoria, Australia: Penguin, 1969.

31. Ronald N. Bracewell. The Fourier Transform and its Applications. McGraw-Hill Book Company, 1986.

32. Simon, G. Information-processing analysis of perceptual processes in problem solving // Psychol. Review. 1969.

33. Shannon C. An algebra for theoretical genetics, Ph.D. Thesis, Massachusetts Institute of Technology, 1940.

34. Shuter, R.: The psychology of musical ability. London: Methuen, 1968.

35. Wiener, N.: God and golem, inc. Cambridge: Massachusetts Institute of Engineering, 1964. 